\title{
Cloud base vertical velocity statistics: a comparison between an atmospheric mesoscale model and remote sensing observations
}

\author{
J. Tonttila ${ }^{1,3}$, E. J. O'Connor ${ }^{1,2}$, S. Niemelä ${ }^{1}$, P. Räisänen ${ }^{1}$, and H. Järvinen ${ }^{1}$ \\ ${ }^{1}$ Finnish Meteorological Institute, P.O. Box 503, 00101 Helsinki, Finland \\ ${ }^{2}$ Meteorology Department, University of Reading, Reading, UK \\ ${ }^{3}$ Division of Atmospheric Sciences, Department of Physics, University of Helsinki, Helsinki, Finland
}

Received: 2 March 2011 - Published in Atmos. Chem. Phys. Discuss.: 22 March 2011

Revised: 26 August 2011 - Accepted: 30 August 2011 - Published: 7 September 2011

\begin{abstract}
The statistics of cloud base vertical velocity simulated by the non-hydrostatic mesoscale model AROME are compared with Cloudnet remote sensing observations at two locations: the ARM SGP site in central Oklahoma, and the DWD observatory at Lindenberg, Germany. The results show that AROME significantly underestimates the variability of vertical velocity at cloud base compared to observations at their nominal resolution; the standard deviation of vertical velocity in the model is typically $4-8$ times smaller than observed, and even more during the winter at Lindenberg. Averaging the observations to the horizontal scale corresponding to the physical grid spacing of AROME $(2.5 \mathrm{~km})$ explains $70-80 \%$ of the underestimation by the model. Further averaging of the observations in the horizontal is required to match the model values for the standard deviation in vertical velocity. This indicates an effective horizontal resolution for the AROME model of at least $10 \mathrm{~km}$ in the presented case. Adding a TKE-term on the resolved grid-point vertical velocity can compensate for the underestimation, but only for altitudes below approximately the boundary layer top height. The results illustrate the need for a careful consideration of the scales the model is able to accurately resolve, as well as for a special treatment of sub-grid scale variability of vertical velocities in kilometer-scale atmospheric models, if processes such as aerosol-cloud interactions are to be included in the future.
\end{abstract}

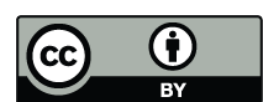

Correspondence to: J. Tonttila (juha.tonttila@fmi.fi)

\section{Introduction}

The vertical component of atmospheric motions, typically on the order of $1-10 \mathrm{~cm} \mathrm{~s}^{-1}$, is generally much weaker than its horizontal counterpart, often by 2 orders of magnitude when examined at the synoptic scale. In spite of their relatively small magnitude, vertical motions are necessary in maintaining the global energy cycle and shaping the temperature structure of the atmosphere. In particular, they play a central role in the formation of clouds and precipitation.

Treatment of vertical velocities in atmospheric models, such as numerical weather prediction (NWP) models, varies depending on the assumptions in the model dynamics. NWP models can be divided into two broad classes, hydrostatic and non-hydrostatic. Hydrostatic models assume hydrostatic balance, where the weight of an air parcel is balanced by the vertical pressure gradient force. This is usually a good approximation at the synoptic scale, and is therefore generally applied in global-scale climate and NWP models. At smaller scales (below $10 \mathrm{~km}$ ), the hydrostatic assumption becomes increasingly inaccurate and, therefore, many mesoscale NWP and fine-scale models (such as cloudresolving and large-eddy models) are non-hydrostatic; the vertical velocity tendency is non-zero and a prognostic equation is employed for the vertical wind.

An important application for vertical velocity in numerical models is the cloud activation of aerosols and calculation of cloud droplet number concentration (CDNC). This process is heavily affected by the maximum supersaturation achieved in a cloud layer; a higher supersaturation makes it possible for smaller and, thus, more numerous aerosol particles to act as cloud condensation nuclei, potentially resulting in a higher CDNC. The maximum supersaturation depends mainly on the rate of condensation on cloud droplets, and

Published by Copernicus Publications on behalf of the European Geosciences Union. 
on the adiabatic cooling of a rising parcel of air. In current state-of-the-art aerosol activation schemes the adiabatic cooling rate is usually given by the vertical velocity of a rising parcel of air (Abdul-Razzak and Ghan, 2000; Fountoukis and Nenes, 2005). In large-scale models vertical velocity poses a challenge because of their quite coarse horizontal grid resolution. Large grid spacing tends to damp the vertical velocity values, as they essentially represent a mean over the grid box area. Large-scale models, therefore, often use a vertical velocity parameterization (e.g. Lohmann et al., 1999; Ghan et al., 1997), whose purpose is to account for the influence of sub-grid scale variability of vertical velocity on cloud activation.

Observations of vertical velocities, along with very highresolution model simulations, are important in the development of model parameterizations describing the above mentioned coupling between atmospheric dynamics and cloud formation and development. Measuring vertical velocities in the atmosphere is difficult, mostly because of their relatively small magnitude. In-situ measurements are, in practice, only possible with research aircraft (Duynkerke et al., 1999; Rodts et al., 2003; Snider et al., 2003; Guo et al., 2008; Lu et al., 2009; Ghate et al., 2010), although mast measurements can be made in layers close to the surface (up to an altitude of a few hundred meters). The aircraft measurements are usually related to intensive field campaigns with limited spatial and temporal coverage, which restricts their usability.

Another measurement technique uses remote sensing by vertically pointing Doppler radars and lidars. These instruments can detect the location of cloud as well as the Doppler velocity. The Doppler velocity is, in this case, related to the vertical motion of atmospheric particles (hydrometeors, aerosols, insects) and can be used to derive estimates of the statistics of atmospheric vertical velocities (e.g. Frisch et al., 1995; Feingold et al., 1999; Kollias and Albrecht, 2000; Kollias et al., 2001; O'Connor et al., 2005; Hogan et al., 2009). Similar to in-situ measurements, the vertically pointing remote sensing observations suffer from poor spatial coverage, but they have the important advantage of being able to measure different layers of the atmospheric vertical column simultaneously with good temporal resolution, which is practically impossible to attain with in-situ measurements. Moreover, some research programmes, such as the Atmospheric Radiation Measurement (ARM) programme (Ackerman and Stokes, 2003) and Cloudnet (Illingworth et al., 2007) provide long time series of Doppler measurements covering several years from several stations around the world.

In this study, we use ground-based vertically-pointing Doppler cloud radar measurements to evaluate the ability of the non-hydrostatic regional NWP model AROME (Seity et al., 2010) to simulate the vertical velocity fields. Our focus is on the magnitude of the variability of the resolved vertical velocity at cloud base. The statistics of the simulated cloud base vertical velocities are compared with those from the Doppler radar measurements, with the aim of:
- determining whether high-resolution simulations of vertical velocity from AROME can be used to derive suitable parameterizations of the distribution of vertical velocities within a grid box for global-scale models, such as climate models,

- further assessing the prerequisites of using AROME itself for studies of aerosol-cloud interactions,

- determining the range of spatial scales relevant to the cloud-related circulation that AROME can resolve.

In Sect. 2 we describe the instruments that supply the observations, and, in Sect. 3, we outline the pertinent features of the mesoscale model AROME. Data from both sources require further processing to obtain suitable cloud base vertical velocities for comparison, and this important step is discussed in Sect. 4. The results are reported in Sect. 5 before concluding in Sect. 6.

\section{Observations}

We analyse observations from two sites with zenith-pointing millimeter-wavelength Doppler cloud radars; the Atmospheric Radiation Measurement (ARM) Southern Great Plains (SGP) site in central Oklahoma, US (Clothiaux et al., 1999), and the Deutscher Wetterdienst (DWD) observatory in Lindenberg, Germany. Both sites are also equipped with co-located lidars, ceilometers, and complemented by a suite of surface instruments.

To identify suitable targets from which to infer the vertical motion of the air, we use the Cloudnet target classification product (Illingworth et al., 2007), which utilizes Doppler cloud radar, lidar and/or ceilometer, dual-wavelength microwave radiometer, raingauge and NWP model data to distinguish between, and categorize, different types of particles and hydrometeors (such as liquid cloud droplets, ice particles, liquid precipitation, drizzle, insects and aerosol). All instruments are processed and averaged to a common timeheight grid with a nominal temporal resolution of $30 \mathrm{~s}$.

The Doppler cloud radar at SGP is the $35 \mathrm{GHz}$ millimeterwavelength cloud radar, MMCR (Clothiaux et al., 1999), which has a number of operational modes; we therefore use the Active Remote Sensing of Clouds (ARSCL) dataset (Clothiaux et al., 2000, 2001) as input to the Cloudnet processing scheme. The ensuing vertical resolution is approximately $90 \mathrm{~m}$. The Doppler cloud radar at Lindenberg is the $35.5 \mathrm{GHz}$ MIRA and the vertical resolution of the Cloudnet product is approximately $30 \mathrm{~m}$. The intrinsic error in the mean Doppler velocity is smaller than the bin width of the measured Doppler spectrum and, hence, for both Doppler cloud radars, the Doppler velocity resolution is on the order of $2 \mathrm{~cm} \mathrm{~s}^{-1}$.

Cloudnet processed data from both sites is available for the years 2004-2009; for this paper we have taken the months 
of January and June. The Lindenberg site provides a quite different climatic regime, compared to SGP, offering greater low-cloud occurrence (with more cases of stratiform cloud decks), whereas SGP presents more scattered cloud characteristics.

\section{AROME mesoscale model}

AROME (Applications of Research to Operations at MEsoscale; Seity et al., 2010) is a limited-area, mesoscale numerical weather prediction model originally designed by Meteo-France. The model is further developed together by the HIRLAM-programme group (10 European countries) and Meteo-France. The model has a non-hydrostatic compressible atmosphere with a semi-Lagrangian advection scheme. The physical parameterizations of the model use a three-dimensional rectangular grid, while the dynamics are solved in spectral space.

The physical parameterizations in AROME are mostly adopted from the MESO-NH model (Lafore et al., 1998). These include a turbulence scheme (Cuxart et al., 2000) providing prognostic turbulent kinetic energy, TKE, and a bulk microphysics scheme with 5 prognostic variables for different water species: cloud water and ice mixing ratios, and mixing ratios for liquid rain, snowfall and graupel (Pinty and Jabouille, 1998). In addition, AROME has a statistical subgrid cloud scheme based on saturation adjustment, where cloud cover is calculated using a probability density function, whose variance depends on the saturation deficit (Bechtold et al., 1995). Rainfall is described statistically as well, so that the fall speeds of different sized precipitation particles are described by a probability density function (Geleyn et al., 2008). The contribution of shallow, non-precipitating cumulus convection and dry thermals is parameterized in terms of the vertical mass flux and properties in the convective updrafts by an eddy diffusion mass flux scheme, EDMF (as described in Pergaud et al., 2009). The effect of the surface on the atmospheric boundary layer is taken into account via fluxes of momentum, heat and moisture, which are provided by the surface module SURFEX (Le Moigne, 2009). Each grid box is divided into four tiles: land, urban, sea, and inland waters. The fluxes from each tile are then areal-averaged in order to determine the net effect for the whole grid box. The radiation scheme is based on ECMWF's radiation code (Fouquart and Bonnel, 1980; Morcrette, 1991; Mlawer et al., 1997).

\subsection{Model setup}

The model was run with domains centred on each observation site $(300 \times 300$ grid points for the SGP domain, $160 \times 160$ gridpoints for the Lindenberg domain), providing 12-h forecasts with output at 3-hourly intervals. For both domains, analyses from the operational Integrated Forecasting System
(IFS) at ECMWF were used to provide the initial model state, and lateral boundary conditions were updated every $6 \mathrm{~h}$ from IFS forecasts. For both experiments, the horizontal resolution of the model was $2.5 \mathrm{~km}$, with a $60 \mathrm{~s}$ time step. Vertical discretization uses terrain-following hybrid coordinates (40 levels) with a resolution of approximately $30 \mathrm{~m}$ close to the surface, gradually increasing to a few hundred meters through the troposphere (8 levels within the lowest $1000 \mathrm{~m}$ ). With a $2.5 \mathrm{~km}$ grid spacing, large convective flow structures are assumed to be resolved explicitly and, therefore, the parameterization for deep convection was not switched on for this particular model configuration. Model output was generated for the months of January and June for 2008 at both SGP and Lindenberg.

\section{Determination of cloud base vertical velocity}

This section focuses on the assessment of the probability density function (PDF) of cloud base vertical velocity and its variance, as retrieved from the AROME and the Cloudnet datasets. The goal is to provide a simple evaluation of the statistical aspects of model-generated vertical velocities at cloud base.

\subsection{Model data}

There is no unique approach to determine cloud boundaries and cloud base vertical velocities from model data. In this study, a threshold value for the AROME grid-cell fractional cloudiness is used. The cloud base height is taken as the altitude of the lowest model level containing liquid cloud water only and with a cloud fraction value exceeding 0.5. Precipitating cloud layers, along with ice-phase or mixed-phase cloud bases are discarded from the analysis in order to match the processing of the model data and the screening applied on the observations as described in Sect. 4.2. Only the base of the lowest cloud layer in each grid column is taken into consideration. Similar cloud fraction threshold was also used to determine the cloud top.

After determining the cloud base level using the criteria above, the cloud base vertical velocity is taken as the corresponding resolved value of vertical velocity. The cloud fraction value at cloud base is used as a weighting factor in the calculation of the vertical velocity statistics. Because the fractional cloudiness values are often close to 0 or 1 for the $2.5 \mathrm{~km}$ grid of AROME, with only a relatively small number of grid points having intermediate values, the effect of these weighting factors is relatively weak. Additionally, the Ushaped distribution of cloud fraction values in this model facilitates the use of a cloud fraction threshold of 0.5 for cloud detection; the results are not sensitive to the actual threshold value chosen.

Note that, although the model does contain a parameterization of the sub-grid updraft vertical velocity inside the 

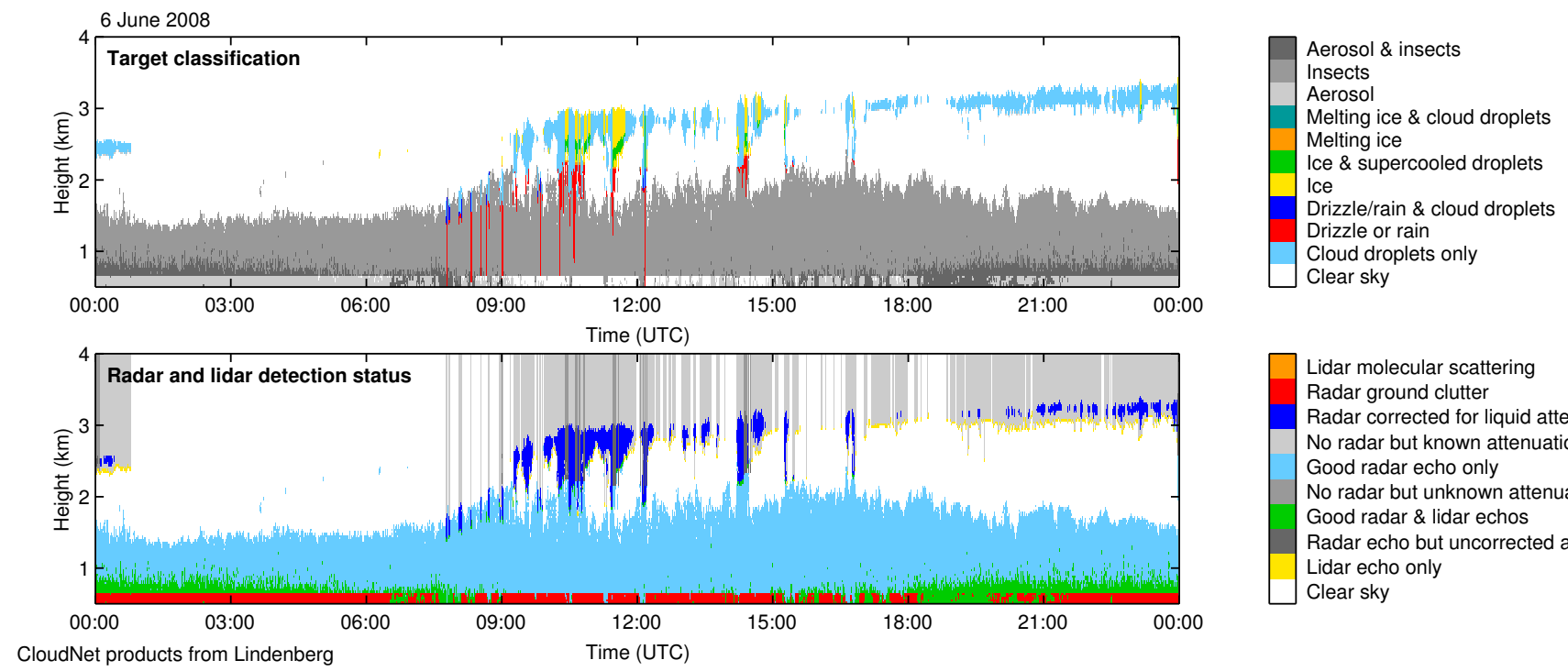
Lidar molecular scattering Radar ground clutter Radar corrected for liquid atten. No radar but known attenuation Good radar echo only
No radar but unknown attenuation Good radar \& lidar echos
Radar echo but uncorrected atten. Lidar echo only Clear sky

Fig. 1. Cloudnet classification product for Lindenberg on 6 June 2008.

EDMF shallow convection scheme, we concentrate on the resolved grid-scale vertical velocity in this analysis. The EDMF-parameterized updraft velocity is essential for representing the updrafts in shallow cumulus clouds as well as for describing the non-local scale mixing by the largest eddies in a convective boundary layer. However, our underlying motivation is in developing a parameterization for large-scale models, and so we prefer not to include the un-resolved components.

\subsection{Observations}

The use of Doppler velocity measurements as a surrogate for the vertical air motion is vulnerable to biases caused by incorrectly including values from targets that have an appreciable terminal velocity. We attempt to minimize these biases by careful inspection and selection of data.

Liquid cloud droplets (with diameters on the order of about $10 \mu \mathrm{m}$ ) typically have very low terminal falling velocities on the order of a few centimeters per second (e.g. Rogers, 1976; Kollias et al., 2001; Khvorostyanov and Curry, 2002). If we limit our considerations to observations with only liquid cloud droplets present, the use of Doppler velocity as a proxy for the vertical air velocity can be justified. The Doppler velocities from cloud bases where rain, drizzle, or ice is also present must be discarded as these hydrometeors have significant terminal velocities. Likewise, small insects are not passive tracers and their mean vertical motion can exhibit significant bias (Geerts and Miao, 2005). These targets are identified within the Cloudnet classification product, which is then used to identify the lowest observed suitable liquid cloud base height and, hence, the cloud base vertical velocity (taken as the mean Doppler velocity at this altitude).
To illustrate the necessity of removing unwanted targets, we concentrate briefly on the results for one day, 6th June 2008, at Lindenberg. The Cloudnet classification product for this day is given in Fig. 1, displaying the various targets identified for a liquid layer lying close to the freezing level (potentially supercooled), including rain, drizzle and ice. Two segments of data have been sampled to produce cloud base vertical velocity distributions; one from 09:00 UTC to 15:00 UTC containing drizzle (and rain and ice cloud events) interspersed with drizzle-free liquid layers; and one from 18:00 UTC to 24:00 UTC that is completely drizzle-free. The vertical velocity distribution for the completely drizzle-free segment, given in Fig. 2a, is reasonably symmetric about $0 \mathrm{~m} \mathrm{~s}^{-1}$. For the segment which includes additional targets, two vertical velocity distributions are produced. Figure $2 b$ contains cloud base vertical velocity values where drizzle co-exists within, or is detected below, the liquid layer. Figure $2 \mathrm{c}$ contains, in addition to drizzle, vertical velocity values where ice co-exists within, or is detected just above, the liquid layer. Figure $2 \mathrm{~b}$ and $\mathrm{c}$ show an obvious negative velocity bias and, as expected, a second, strongly negative, mode. One direct consequence is a significant broadening of the distribution, clearly displaying the effect of large hydrometeors on the vertical velocity distribution. If not detected and removed, drizzle will therefore increase the risk of bias in the results.

Drizzle is, in fact, a serious concern and can be difficult to detect in-cloud. As an additional precaution, a maximum threshold for radar reflectivity is used. Earlier studies have employed thresholds, such as $-17 \mathrm{dBZ}$ (Frisch et al., 1995; Feingold et al., 1999; Ghate et al., 2010), to delineate drizzle from drizzle-free clouds, but, since our interest is specifically on the vertical velocities at cloud base, where cloud droplets 

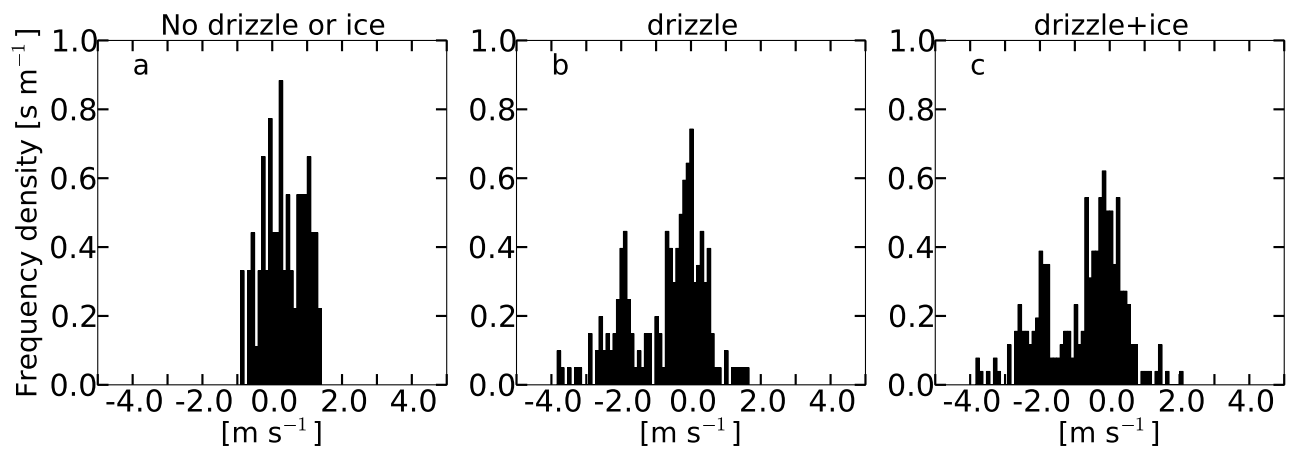

Fig. 2. Observed vertical velocity distributions at cloud base for 6 June 2008 at Lindenberg demonstrating a bias caused by fall speed of large particles. (a): liquid cloud droplets only, (b): drizzle included, (c): ice particles and drizzle included. Velocity is positive upwards.

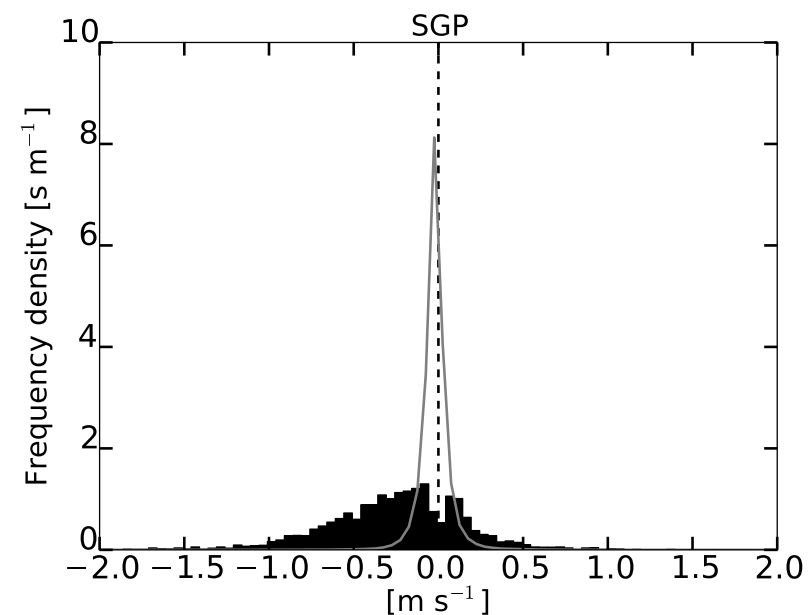

Fig. 3. Distribution of cloud base vertical velocity at SGP in January for AROME (grey line) and Cloudnet observations (filled black bars) for cloud bases between 1000 and $1500 \mathrm{~m}$. The vertical velocity bin width is $0.05 \mathrm{~m} \mathrm{~s}^{-1}$ in both cases.

are at their smallest and drizzle drops presumably at their largest, a maximum value of $-30 \mathrm{dBZ}$ is used in this study (see Liu et al., 2008; Kollias and Albrecht, 2010). These constraints limit our investigation to a rather small fraction of the total number of observed liquid cloud layers.

\section{Results}

\subsection{Direct comparison with observations}

\subsubsection{General overview}

The vertical velocities at cloud base from both AROME and Cloudnet datasets are apportioned into $500 \mathrm{~m}$ bins according to altitude. The lowest cloud base height bin is $500-1000 \mathrm{~m}$ while the highest is limited to around 3000-3500 m (2000$2500 \mathrm{~m}$ during winter), because the number of observations

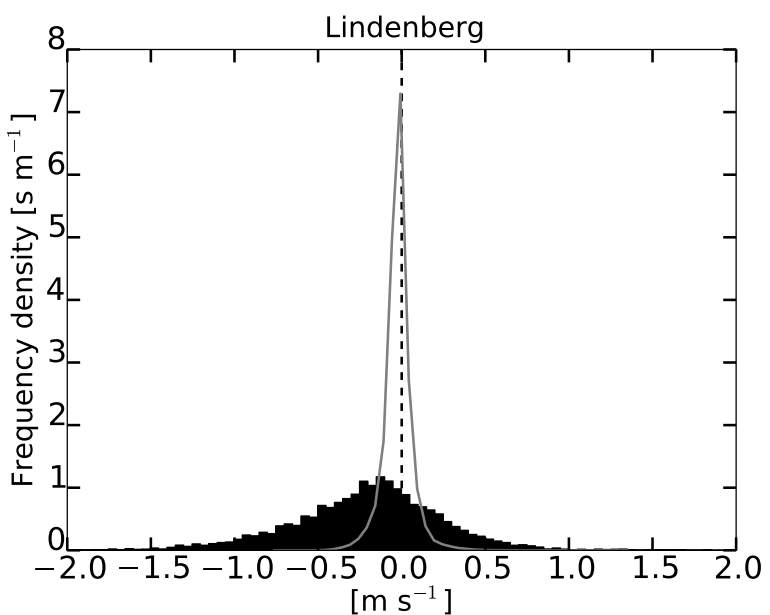

Fig. 4. Same as Fig. 3, but for Lindenberg.

with liquid cloud droplets decreases rapidly at higher altitudes. Figures 3 and 4 illustrate cloud base vertical velocity histograms from SGP and Lindenberg in January for a single cloud base altitude bin (between 1000 and $1500 \mathrm{~m}$ ). These are representative of the typical differences between modelled and observed velocity distributions. The vertical velocity histograms from AROME are quite narrow (standard deviation of about $0.1 \mathrm{~m} \mathrm{~s}^{-1}$ at both sites), with a slight positive skewness (similar to results found by Zhu and Zuidema, 2009) and a mean close to zero. In contrast, the observed vertical velocities exhibit much wider distributions at both sites (standard deviation of about $0.4-0.5 \mathrm{~m} \mathrm{~s}^{-1}$ ). The observations tend to show a slight preponderance towards negative velocities, leading to a negative mean value in the distribution. The velocity distributions at all altitudes are qualitatively similar.

Figure $5 \mathrm{a}$ and $\mathrm{b}$ display the distribution mean vertical velocity as a function of height for January and June at SGP and Lindenberg. In January, the mean vertical velocity (Fig. 5a) in AROME is very close to zero in both domains. This is 

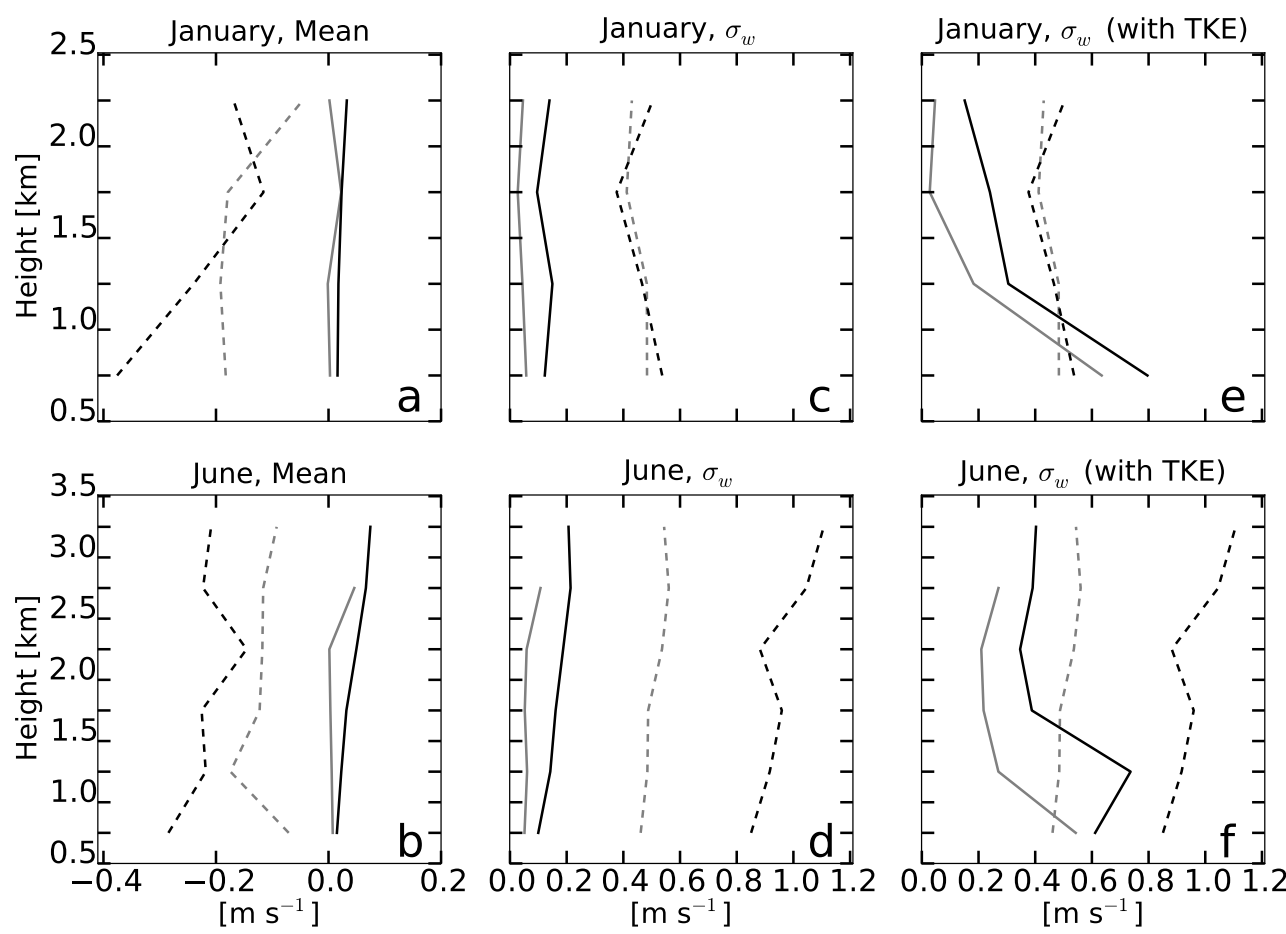

\begin{tabular}{|llll|}
\hline- & AROME SGP & - & AROME Lindenberg \\
$-\cdots$ & Cloudnet SGP & -- & Cloudnet Lindenberg \\
\hline
\end{tabular}

Fig. 5. Vertical velocity distribution statistics as a function of height at SGP (black) and Lindenberg (grey) for AROME (solid) and observations (dashed): (a, b) mean vertical velocity, $(\mathbf{c}, \mathbf{d})$ standard deviation $\left(\sigma_{w}\right),(\mathbf{e}, \mathbf{f}) \sigma_{w}$ when a TKE-term has been added to the modelled vertical velocities (see text).

also true in June (Fig. 5b) for Lindenberg, while for SGP, AROME now displays positive mean values, although still below $0.1 \mathrm{~m} \mathrm{~s}^{-1}$. In contrast, the observations show a consistent negative mean value, typically from $-0.1 \mathrm{~m} \mathrm{~s}^{-1}$ to $-0.3 \mathrm{~m} \mathrm{~s}^{-1}$ at all heights and for both January and June, although values as low as $-0.4 \mathrm{~m} \mathrm{~s}^{-1}$ are seen at SGP in January close to the surface. Since the vertical velocity averages are expected to approach zero (or slightly positive values in cloud, similar to the results for AROME) over a long period of time, the negative mean value most likely represents a bias due to occasional large hydrometeors or other particles (as discussed in Frisch et al., 1995; Kollias and Albrecht, 2000; O'Connor et al., 2005), where the associated velocities have not been rejected even after the strict qualification for the selection of drizzle-free cloud base vertical velocities.

One other factor that might contribute to the largest negative mean velocities seen at SGP is the slope of the land surface around the observation site, which is characterized by a height difference roughly on the order of $100 \mathrm{~m}$ along a horizontal west-east oriented section of $100 \mathrm{~km}$. In case of a strong horizontal flow from the west, which occurs rather frequently at SGP in winter, the contribution by negative, or downward, vertical velocities in the observations and the model could be increased. The impact of the surface slope on our results was investigated by filtering out vertical velocity data under the influence of strong westerly flow $\left(\geq 15 \mathrm{~m} \mathrm{~s}^{-1}\right)$. Although not shown here in detail, the observed mean vertical velocity of almost $-0.4 \mathrm{~m} \mathrm{~s}^{-1}$ was increased to about $-0.2 \mathrm{~m} \mathrm{~s}^{-1}$ after the filtering for the lowest cloud base levels at SGP in January. In other cases (i.e. higher-altitude cloud base in January and all cases in June) the filtering had only a small or negligible impact on the mean values, both for the observations and for the model data at SGP. Thus we conclude that this issue is less important than the retrieval artefacts mentioned above.

Of potentially more importance is the variability in vertical velocity at cloud base, here investigated by taking the standard deviation of the vertical velocity distributions, $\sigma_{w}$. It is immediately clear from Fig. $5 \mathrm{c}$ and $\mathrm{d}$ that the observed values of $\sigma_{w}$ are always larger than their corresponding model values. In January, the observed $\sigma_{w}$ values range from 0.4$0.5 \mathrm{~m} \mathrm{~s}^{-1}$ at both sites, while the model values are approximately $0.1 \mathrm{~m} \mathrm{~s}^{-1}$ or less. AROME thus underestimates $\sigma_{w}$ typically by a factor of 4-8 in January (for Lindenberg, in the worst case, by a factor 10). In June at Lindenberg, the observed $\sigma_{w}$ is slightly larger $\left(0.5-0.6 \mathrm{~m} \mathrm{~s}^{-1}\right)$, while $\sigma_{w}$ in AROME is almost similar to January values. At SGP in June, the observed $\sigma_{w}$ is $0.8-1.1 \mathrm{~m} \mathrm{~s}^{-1}$ consistently across all altitudes. The $\sigma_{w}$ values in AROME at SGP in June are also larger, ranging now from $0.1 \mathrm{~m} \mathrm{~s}^{-1}$ close to the surface, to 


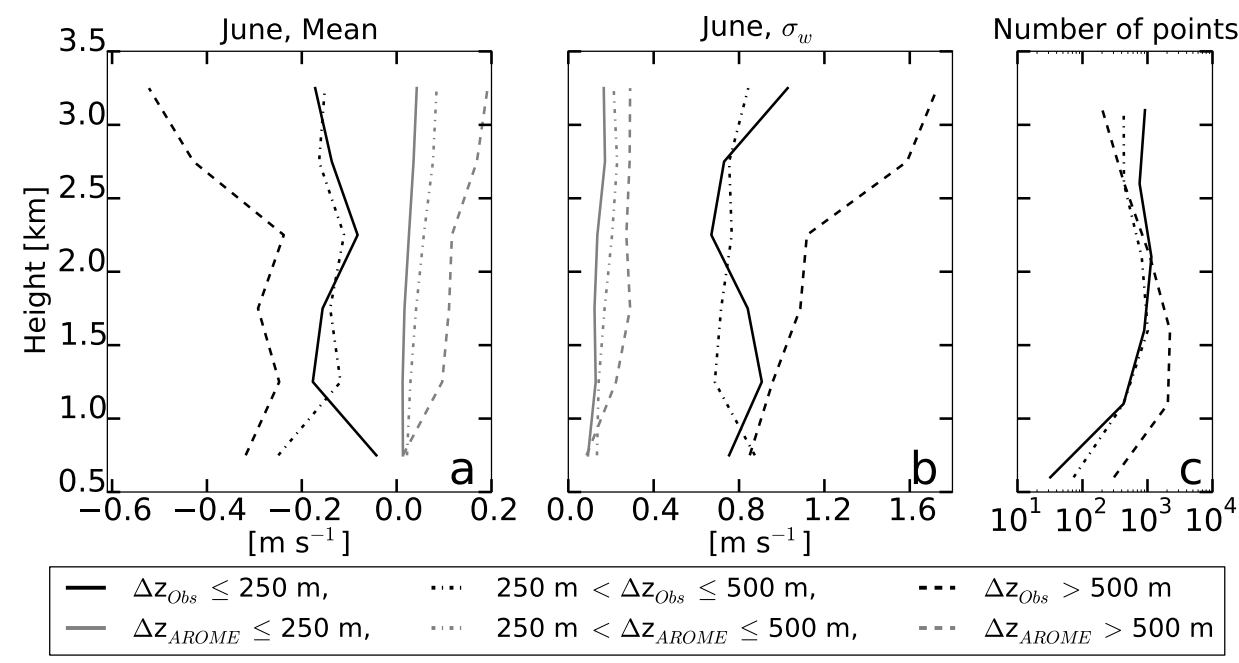

Fig. 6. Observed (black) and modelled (grey) vertical velocity distribution parameters at SGP in June for clouds classified by their geometrical thickness $(\Delta z)$ (solid lines for $\Delta z \leq 250 \mathrm{~m}$, dash-dot lines for $250<\Delta z \leq 500 \mathrm{~m}$ and dashed lines for $\Delta z \geq 500 \mathrm{~m}$ ). (a) mean vertical velocity, (b) standard deviation $\left(\sigma_{w}\right)$, (c) number of points for the observations (for AROME, the number of points is larger for all cases, while the shapes of the profiles are qualitatively rather similar).

$0.2 \mathrm{~m} \mathrm{~s}^{-1}$ at higher altitudes. In June, AROME thus underestimates $\sigma_{w}$ by a factor of 5-6 at SGP, whereas the underestimation at Lindenberg is approximately by a factor of 8 . Typical values (means over the vertical profile) for both the modelled and observed $\sigma_{w}$ are given in Table 1.

As described in more detail in Sect. 5.2 below, the underestimation of $\sigma_{w}$ in AROME occurs because a large proportion of the cloud base vertical velocity variability is at spatial scales AROME does not resolve. To account for the unresolved variability, numerical models may include an additional term for vertical velocity, often based on TKE. This is demonstrated in Fig. 5e and $\mathrm{f}$, where $\sigma_{w}$ is now calculated using a cloud base vertical velocity, $w$, given by $w=\bar{w}+a \cdot \sqrt{\mathrm{TKE}}$, where $\bar{w}$ is the grid-scale vertical velocity and TKE is the corresponding value for turbulent kinetic energy. This formulation is similar to the parameterization by Lohmann et al. (1999) commonly used in climate models, with the exception that we now allow the sign of the second term to be both positive and negative: the parameter $a$ is set -1 (for negative $\bar{w}$ ) or 1 (for positive $\bar{w}$ ). The value of $a= \pm 1$ is chosen for simplicity in order to illustrate the qualitative effect of adding the TKE term, though use of $a \neq \pm 1$ could potentially provide a better fit with the observations. This way, the mean velocity remains almost unchanged (not shown), while a significant increase is seen in $\sigma_{w}$ at altitudes below about 1-2 km (approximately the height of the boundary layer top), where it now has values on the same order of magnitude as the observed $\sigma_{w}$ (Fig. 5e and f). At higher altitudes, the TKE-term is small, which is partially attributable to the use of the EDMF-scheme representing non-local turbulent mixing by the largest eddies as well as the vertical fluxes of heat, moisture and momentum inside shallow convective
Table 1. Typical $\sigma_{w}$ for the observations (AROME) in $\mathrm{m} \mathrm{s}^{-1}$ at Lindenberg and SGP in January and June.

\begin{tabular}{ccc}
\hline$\sigma_{w}$ & January & June \\
\hline Lindenberg & $0.45(0.05)$ & $0.51(0.07)$ \\
SGP & $0.47(0.13)$ & $0.96(0.17)$
\end{tabular}

clouds outside the boundary layer (Pergaud et al., 2009). Because of this, the use of a TKE-term does not fully represent the variability of vertical velocity at sub-grid scales in our results.

\subsubsection{Classification by cloud depth}

We now investigate whether there is any distinction between shallow stratiform cloud-layers and deeper cumulus clouds. For this we use cloud geometrical thickness, which is directly applicable to both the model data and the observations. Figure 6 displays the statistics of vertical velocity for three subclasses, separated by cloud geometrical thickness $(0-250 \mathrm{~m}$, $250-500 \mathrm{~m}$ and $>500 \mathrm{~m})$. The results are presented only for SGP in June due to the higher occurrence of relatively deep clouds.

The mean values of cloud base vertical velocity simulated by AROME tend to increase with cloud geometrical thickness, as shown by Figure 6a, while the observed mean value becomes more negative for the deepest clouds only (most likely because of a bias due to selective sampling in the screening procedure, see below). Similarly, $\sigma_{w}$ (Fig. 6b) tends to increase gradually in AROME with increasing cloud 
geometrical thickness, although $\sigma_{w}$ for the deepest cloud class only reaches about $0.3 \mathrm{~m} \mathrm{~s}^{-1}$. However, the observations show little difference between the two shallow classes and a significant increase in $\sigma_{w}$ is only seen for the deep clouds ( $>500 \mathrm{~m}$ thick), with the largest values exceeding $1.6 \mathrm{~m} \mathrm{~s}^{-1}$.

An implicit assumption in the analysis is that the Doppler radar observes a random section of each cloud passing overhead. The screening procedure has the potential to introduce an artificial bias if the sampling statistics are skewed towards particular profiles (e.g. descending edges of cumulus clouds rather than ascending precipitating cores). For shallow clouds in an ideal case, the sampling statistics appear to be essentially unbiased as shown in Fig. 2a, where no profiles were discarded. Figure 6a shows that the two shallow cloud classes in the observations (both $<500 \mathrm{~m}$ deep) have a negative mean vertical velocity $\left(-0.2 \mathrm{~m} \mathrm{~s}^{-1}\right)$, which is similar to that seen in the overall sampling (Fig. 5b), and attributable to retrieval artefacts. However, for the deep clouds, the risk of conditionally sampling the cloud edges by discarding the precipitating profiles is increased (presumably the profiles with an updraft for cumulus clouds). We think this may be responsible for the additional increase in the negative mean vertical velocity (from -0.2 to $-0.5 \mathrm{~m} \mathrm{~s}^{-1}$ with increasing cloud depth).

\subsubsection{Effect of bias on the comparison of $\sigma_{w}$}

The direct comparison of $\sigma_{w}$ does not account for the negative bias caused by retrieval artefacts in the observations (Fig. 5a and b). To investigate how the bias affects this comparison, we next calculate the root mean square (RMS) values separately for the positive (RMS+) and negative (RMS-) portions of the vertical velocity distributions. By this experiment we attempt to show that the negative bias in the observations does not significantly alter the shape of the distribution and, most importantly, the value of $\sigma_{w}$. If we assume that the negative bias is a true bias and affects the entire distribution equally, we would then expect the observed RMSto be consistently larger than the observed RMS+. In contrast, RMS+ values from unbiased model velocity distributions should be approximately similar to RMS- values, assuming a symmetric distribution shape.

Figure 7 shows that this is indeed the case. Profiles of RMS- and RMS+ are plotted for the modelled and observed velocity distributions over both domains for the months of January and June. The observed RMS- is consistently approximately $50 \%$ larger than the observed RMS+ at both sites in both January and June, whereas the model RMS- is usually slightly smaller than RMS+. Observed magnitudes of RMS are much larger than their model counterparts, a consequence of the much larger observed values of $\sigma_{w}$ (Fig. 5c and d).

Theoretically, a normal distribution with a mean of $-0.2 \mathrm{~m} \mathrm{~s}^{-1}$ and $\sigma_{w}=0.5 \mathrm{~m} \mathrm{~s}^{-1}$ should result in RMS- being
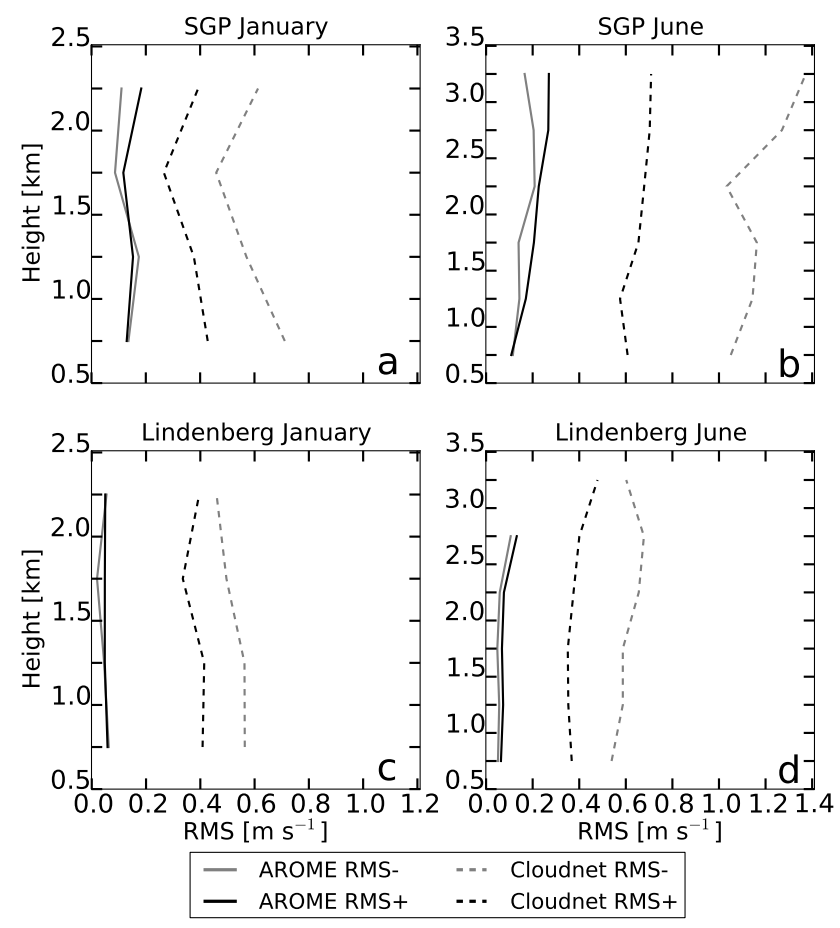

Fig. 7. Profiles of RMS-values calculated separately for negative and positive parts of the vertical velocity PDFs from AROME and the observations.

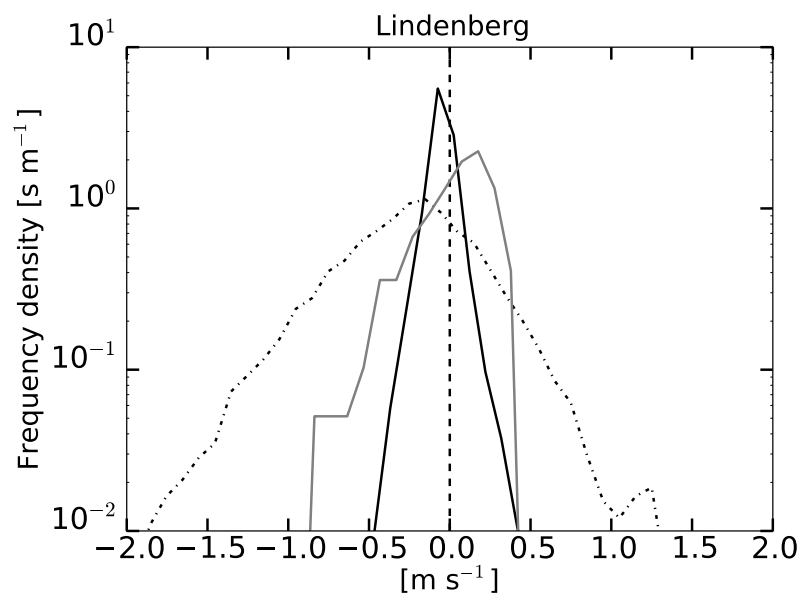

Fig. 8. Case study for Lindenberg, 29-30 January 2008: histograms of vertical velocity for AROME (solid black), observations averaged to $2500 \mathrm{~m}$ scale (solid grey), and observations at their original resolution (black dash-dot line). The vertical dashed line marks the $0 \mathrm{~m} \mathrm{~s}^{-1}$ velocity. Note the logarithmic scaling on the vertical axis. The vertical velocity bin width is $0.1 \mathrm{~m} \mathrm{~s}^{-1}$ for all curves.

larger than RMS+ by a factor of about 1.5 , similar to what is seen in practice. This suggests that we can assume that the bias has had little impact on the observed distribution shape, however, with the important caveat that the observed velocity distribution may not necessarily conform to the ideal. 


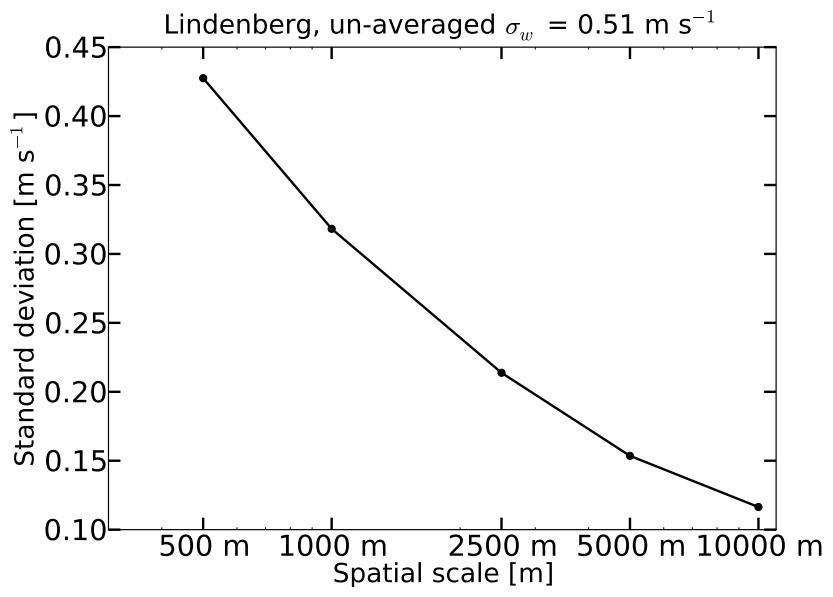

Fig. 9. Case study for Lindenberg, 29-30 January 2008: $\sigma_{w}$ in averaged observations as a function of the spatial averaging scale. For AROME, $\sigma_{w}$ in the corresponding case is approximately $0.08 \mathrm{~m} \mathrm{~s}^{-1}$.

\subsection{Comparison with observations averaged to the model resolution}

To further investigate the effect of changing horizontal resolution and which horizontal scales the model is capable of resolving, we undertake a case study where the observed timeheight cross-sections of vertical velocity are averaged onto different horizontal spatial scales.

The averaging is performed by first converting the time increments in the observations into spatial distances using the horizontal wind velocity from AROME at each height as an advection speed. The scales selected for averaging range from $500 \mathrm{~m}$ to $10 \mathrm{~km}$. Finding long segments of continuous stratiform cloud decks is a prerequisite for calculating the averages over the desired length scales, while concurrently producing enough data to derive confident statistics. Moreover, as before, we are forced to limit our considerations to clouds with only liquid droplets. Only a handful of such realizations were covered by both the model data and observations. In Figs. 8 and 9, we present the best case, comprising data from Lindenberg for 29-30 January 2008. During this period, the cloud base altitude varied from $1000 \mathrm{~m}$ to $1500 \mathrm{~m}$.

Figure 8 illustrates the effect of averaging on the shape of the distribution of cloud base vertical velocities, where observations averaged to the $2500 \mathrm{~m}$ scale are compared to the observations at their original resolution, and AROME. Figure 9 shows how the observed $\sigma_{w}$, calculated from distributions including those in Fig. 8, behaves as a function of the averaging length scale. It is evident that $\sigma_{w}$ appears to decrease almost exponentially with increasing averaging length. In particular, at the $2500 \mathrm{~m}$ scale, corresponding to the physical grid spacing of AROME, $\sigma_{w}$ is approximately $0.21 \mathrm{~m} \mathrm{~s}^{-1}$, being about $60 \%$ smaller than the observed $\sigma_{w}$ for data at the original resolution $\left(0.51 \mathrm{~m} \mathrm{~s}^{-1}\right)$.
Averaging to the physical grid spacing of AROME is not enough to explain all of the underestimation of $\sigma_{w}$ in the model and, according to Fig. 9, a minimum averaging scale of $10 \mathrm{~km}$ is required for the observations to produce values comparable with the model ( $\sigma_{w}$ for AROME in this case is approximately $0.08 \mathrm{~m} \mathrm{~s}^{-1}$ ). Thus, the grid point values in AROME should be considered to be representative of an effective horizontal resolution rather than the physical grid spacing, as described in Skamarock (2004) through the use of kinetic energy spectra. Depending on the treatment of kinetic energy dissipation at the smallest scales represented by a model, the effective resolution can generally be expected to be around 4-8 times the nominal grid spacing. Thus, obtaining statistics comparable with AROME at an averaging scale of at least $10 \mathrm{~km}$, as seen in Fig. 9, fits within this range.

\section{Discussion and conclusions}

The statistics of vertical velocity at cloud base simulated by the AROME numerical weather prediction model were compared with vertically pointing Doppler radar observations at two sites, the Atmospheric Radiation Measurement programme Southern Great Plains (SGP) site (Oklahoma, US) and Lindenberg (Germany). The main objectives of this comparison were to evaluate the resolved vertical velocity fields simulated by the high-resolution model and assess their suitability for deriving parameterizations of the distribution of vertical velocity within a grid box for global-scale models and for simulating aerosol-cloud interactions.

At the two sites, the mean cloud base vertical velocity simulated by AROME was very close to zero during winter and the standard deviation of cloud base vertical velocity, $\sigma_{w}$, was also very small $\left(<0.1 \mathrm{~m} \mathrm{~s}^{-1}\right)$. A mean vertical velocity close to zero was seen also in summer at Lindenberg in the model data. At SGP, however, a slightly larger positive mean vertical velocity was found for summer, together with an increase in $\sigma_{w}$, attributable to the strong convective nature at this location. Observations at these two sites showed a consistent negative, or downwards, mean vertical velocity at cloud base in both summer and winter, with no shift towards positive values apparent at SGP in summertime. The observed negative mean velocity was recognized as a bias mainly due to contamination of the Doppler retrievals by remaining drizzle and precipitating particles, despite the screening procedures applied on the observed data. We showed that the negative bias does not appear to affect the variability estimates from observations, with similar values of $\sigma_{w}$ found at both sites in winter, and at Lindenberg in summer $\left(0.4-0.5 \mathrm{~m} \mathrm{~s}^{-1}\right)$. For SGP in June, the observations showed a significant increase in $\sigma_{w}$, with the largest values exceeding $1.0 \mathrm{~m} \mathrm{~s}^{-1}$.

For a more detailed investigation, the observed and modelled data were also classified with respect to cloud geometrical thickness. AROME showed gradually increasing positive 
mean velocity and $\sigma_{w}$ with increasing cloud thickness, where the largest mean and $\sigma_{w}$ were approximately $0.2 \mathrm{~m} \mathrm{~s}^{-1}$ and $0.3 \mathrm{~m} \mathrm{~s}^{-1}$, respectively. In the observations, clear differences were seen only for the deepest clouds $(\geq 500 \mathrm{~m})$ with substantial increase in $\sigma_{w}$. For the observed mean velocity, an increase in the negative bias was seen for the deepest clouds as well.

The major finding of this study is that, considering the resolved model fields, AROME significantly underestimates the variability of vertical velocity, when compared to the observations. Overall, $\sigma_{w}$ for the simulated vertical velocity distribution is typically 4-8 times smaller than that of the observed distribution. Classification by cloud depth did not present prominent changes to this conclusion. For the most part, the underestimation is due to the insufficient model resolution; the $2.5 \mathrm{~km}$ physical grid spacing of AROME is clearly too coarse to resolve the details in vertical velocity variations. A portion of cumuliform updraft-downdraft structure will be unresolved as well, since the horizontal scales of updraft cores in cumulus clouds can easily be as little as a few hundred meters (Kollias et al., 2001).

Another aspect that could affect the variability of the resolved vertical velocity fields relates to the use of the eddy diffusion mass flux (EDMF) scheme. In conditions where the EDMF-scheme is used to describe the vertical in-cloud transport of heat and moisture, the scheme acts to stabilize the atmospheric column. This would then, in part, contribute to the underestimation of the resolved grid-scale vertical velocity.

The importance of horizontal resolution was studied further by applying a method of averaging to the vertical velocity observations. At the scale of the physical grid spacing of AROME, the value $\sigma_{w}$ from averaged observations was still slightly larger than that in AROME data. This illustrates the fact that the grid point values of vertical velocity should be considered to represent an effective resolution, (similar to the results of Skamarock, 2004). As noted in Sect. 5.2, a minimum averaging scale of $10 \mathrm{~km}$ was needed for the observations to produce statistics comparable with AROME in a case study for Lindenberg. This suggests that the effective resolution of AROME is at least 4-5 times the physical grid spacing of the model, though in a more general case we would expect to see a slightly coarser estimate. Nevertheless, the effective resolution is an important aspect that has to be accounted for in physical processes involved with vertical velocity.

The influence of grid resolution on vertical velocity fields has been noted elsewhere as well; in their extensive largeeddy simulations, Khairoutdinov et al. (2009) reported a significant decrease in the magnitudes of vertical velocities in convective updraft cores as the horizontal grid spacing of the model was increased gradually from $100 \mathrm{~m}$ to $1.6 \mathrm{~km}$. Moreover, it has been noted that also the vertical resolution of a model has an effect on the representation of vertical velocities. Guo et al. (2008) suggested that a vertical resolution of about $10 \mathrm{~m}$ is needed to robustly resolve the higher order statistical moments of vertical velocities.

A realistic description of the small-scale vertical velocity distribution is necessary for modelling microphysical processes such as aerosol-cloud interactions. Using the resolved values of vertical velocity at model grid-points to calculate the cloud activation of aerosols can result in an underestimation of the cloud droplet number concentration (CDNC), even in kilometer-scale models (this is shown here through direct comparison of vertical velocity, rather than by simulating the actual activation process). This problem was noted, e.g., by Ivanova and Leighton (2008), who used a non-hydrostatic model with a $3 \mathrm{~km}$ horizontal resolution to simulate the cloud activation of aerosols. CDNC was underestimated considerably when using the grid-scale vertical velocities simulated directly by their model. The same issue was highlighted also by Zubler et al. (2011) in their experiments with a regional climate model at a horizontal resolution of $50 \mathrm{~km}$, as well as in the study by Bangert et al. (2011). One commonly-used approach currently is to compensate for this discrepancy by calculating an effective vertical velocity with a TKE-based parameterization (Lohmann et al., 1999), although other approaches (based e.g. probability density functions) also exist (Ghan et al., 1997; Hoose et al., 2010). The addition of a TKE-term was also attempted for AROME in our analysis (Fig. 5c and 5f), where it was found useful only for altitudes below approximately the height of the boundary layer top.

The rather coarse scale that the resolved fields simulated by AROME represent, in terms of cloud related circulation, sets limitations to their usability for developing parameterizations for larger-scale models. Even so, AROME does resolve much finer-scale circulation features than e.g. global climate models, and therefore, the data simulated by AROME could provide useful information on the physical aspects of the cloud-related circulations.

Considering the possibility of including parameterizations of aerosol-cloud interactions inside AROME (or other similar model configuration), the treatment of sub-grid vertical velocity variations is an important prerequisite. One candidate for a partial solution is the cumulus updraft velocity parameterization inside the EDMF-scheme, which could be used to account for the cumulus-portion of the sub-grid variation of vertical velocity in a grid box. However, as stated in Pergaud et al. (2009), one of the key assumptions in the EDMF-scheme is that the area fraction of the shallow convection updraft area is small compared to the grid square area. Therefore another parameterized component for the sub-grid vertical velocity would still be needed for the largescale and stratiform cloud regimes, which cover large fractions of a grid-box. As shown in Fig. 5e-f, the addition of a TKE term to the resolved vertical velocity in this type of model may not produce the desired result in all situations. 
Acknowledgements. We acknowledge the Cloudnet project (European Union contract EVK2-2000-00611) for providing the categorization and classification datasets, which was produced by the University of Reading using measurements from Lindenberg, Germany.

The ARSCL dataset was obtained from the Atmospheric Radiation Measurement (ARM) Program sponsored by the US Department of Energy, Office of Science, Office of Biological and Environmental Research, Climate and Environmental Sciences Division.

This work has been supported by the Academy of Finland (project number 127210).

We also thank the two anonymous reviewers for their suggestions and comments especially on investigating the inclusion of a TKE-term in the analysis and its implications on the model results.

Edited by: J. Quaas

\section{References}

Abdul-Razzak, H. and Ghan, S. J.: Parameterization of aerosol activations 2. Multiple aerosol types. J Geophys. Res., 105(D5), 6837-6844, doi:10.1029/1999JD901161, 2000.

Ackerman, T. P. and Stokes, G.: The Atmospheric Radiation Measurement program. Phys. Today, 56, 38-44, doi:10.1063/1.1554135, 2003.

Bangert, M., Kottmeier, C., Vogel, B., and Vogel, H.: Regional scale effects of the aerosol cloud interaction simulated with an online coupled comprehensive chemistry model, Atmos. Chem. Phys., 11, 4411-4423, doi:10.5194/acp-11-4411-2011, 2011.

Bechtold, P., Cuijpers, J. W. M., Mascart, P., and Trouilhet, P.: Modelling of trade wind cumuli with a low-order turbulence model: Toward a unified description of $\mathrm{Cu}$ and Sc clouds in meteorological models. J. Atmos. Sci., 52, 455-463, 1995.

Clothiaux, E. E., Moran, K. P., Martner, B. E., Ackerman, T. P., Mace, G. G., Uttal, T., Mather, J. H., Widener, K. B., Miller, M. A., and Rodriguez. D. J.: The Atmospheric Radiation Measurement Program Cloud Radars: Operational Modes. J. Atmos. Ocean. Tech., 16, 819-827, 1999.

Clothiaux, E. E., Ackerman, T. P., Mace, G. G., Moran, K. P., Marchand, R. T., Miller, M. A., and Martner, B. E.: Objective Determination of Cloud Heights and Radar Reflectivities Using a Combination of Active Remote Sensors at the ARM CART Sites, J. Appl. Meteorol., 39, 645-665, 2000.

Clothiaux, E. E., Miller, M. A, Perez, R. C., Turner, D. D., Moran, K. P., Martner, B. E., Ackerman, T. P., Mace, G. G., Marchand, R. T., Widener, K. B., Rodriguez, D. J., Uttal, T., Mather, J. H., Flynn, C. J., Gaustad, K. L., and Ermold, B.: The ARM Millimeter Wave Cloud Radars (MMCRs) and the Active Remote Sensing of Clouds (ARSCL) Value Added Product (VAP). DOE Tech. Memo. ARM VAP-002.1, available online at: http: //www.arm.gov/publications/vaps.stm, 2001.

Cuxart, J., Bougeault, P., and Redelsperger, J. L.: A turbulence scheme allowing for mesoscale and large eddy simulations, Q. J. Roy. Meteorol. Soc., 126, 1-30, 2000.

Duynkerke, P. G., Jonker, P. J., Chlond, A., Van Zanten, M. C., Cuxart, J., Clark, P., Sanchez, E., Martin, G., Lenderink, G., and Teixeira, J.: Intercomparison of three- and one-dimensional model simulations and aircraft observations of stratocumulus, Bound.-Layer Meteorol., 92, 453-487, 1999.
Feingold, G., Frisch, A. S., Stevens, B., and Cotton, W. R.: On the relationship among cloud turbulence, droplet formation and drizzle as viewed by Doppler radar, microwave radiometer and lidar, J. Geophys. Res., 104, 22195-22203, 1999.

Fountoukis, C. and Nenes, A.: Continued development of a cloud droplet formation parameterization for global climate models, J. Geophys. Res., 110, D11212, doi:10.1029/2004JD005591, 2005.

Fouquart, Y. and Bonnel, B.: Computations of solar heating of the Earth's atmosphere: A new parameterization, Beitr. Phys. Atmos., 53, 35-62, 1980.

Frisch, A. S., Lenschow, D. H., Fairall, C. W., Schubert, W. H., and Gibson, J. S.: Doppler radar measurements of turbulence in marine stratiform cloud during ASTEX, J. Atmos. Sci., 52, 2800-2808, 1995.

Geerts, B. andMiao, Q.: The Use of Millimeter Doppler Radar Echoes to Estimate Vertical Air Velocities in the Fair-Weather Convective Boundary Layer, J. Atmos. Oceanic. Technol., 22, 225-246, 2005.

Geleyn, J.-F., Catry, B., Bouteloup, Y., Brozkova, R.: A statistical approach for sedimentation inside a microphysical precipitation scheme, Tellus, 60A, 649-662, 2008.

Ghan, S. J., Leung, L. R., Easter, R. C., and Abdul-Razzak, H.: Prediction of cloud droplet number in a general circulation model, J. Geophys. Res., 102, 21777-21794, 1997.

Ghate, V. P., Albrecht, B. A., and Kollias, P.: Vertical velocity structure of nonprecipitating continental boundary layer stratocumulus clouds, J. Geophys. Res., 115, D13204, doi:10.1029/2009JD013091, 2010.

Guo, H., Liu, Y., Daum, P. H., Senum, G. I., and Tao, W.-K.: Characteristics of vertical velocity in marine stratocumulus: Comparison of large eddy simulations with observations. Environ. Res. Lett., 3, 045020, doi:10.1088/1748-9326/3/4/045020, 2008.

Hogan, R. J., Grant, A. L., Illingworth, A. J., Pearson, G. N., and O'Connor, E. J.: Vertical velocity variance and skewness in clear and cloud-topped boundary layers as revealed by Doppler lidar, Q. J. Roy. Meteorol. Soc., 135, 635-643, 2009.

Hoose, C., Kristjánsson, J. E., Arabas, S., Boers, R., Pawlowska, H., Puygrenier, V., Siebert, H., and Thouron, O.: Parameterization of in-cloud vertical velocities for cloud droplet activation calculations in coarse-grid models: Analysis of observations and cloud resolving model results. 13th Conference on Atmospheric Raditation, Portland, OR, USA, 28 June-2 July 2010, Presentation 6.4, available online at: http://ams.confex.com/ams/pdfpapers/ 170866.pdf, 2010.

Illingworth, A. J., Hogan, R. J., O’Connor, E. J., Bouniol, D., Brooks, M. E., Delanoë, J., Donovan, D. P., Eastment, J. D., Gaussiat, N., Goddard, J. W. F., Haeffelin, M., Klein Baltink, H., Krasnov, O. A., Pelon, J., Piriou, J.-M., Protat, A., Russchenberg, H. W. J., Seifert, A., Tompkins, A. M., van Zadelhoff, G.-J., Vinit, F., Willén, U., Wilson, D. R., and Wrench, C. L.: Cloudnet: Continuous evaluation of cloud profiles in seven operational models using ground-based observations, B. Am. Meteorol. Soc., 88, 883-898, 2007.

Ivanova, I. T., Leighton, H. G.: Aerosol-cloud interactions in a mesoscale model. Part I: Sensitivity to activation and collisioncoalescence, J. Atmos. Sci., 65, 289-308, 2008.

Khairoutdinov, M. F., Krueger, S. K., Moeng, C.-H., Bogenschutz, P. A., and Randall, D. A.: Large-eddy simulation of deep maritime tropical convection. J. Adv. Model. Earth Syst., 1(15), 
13 pp., 2009.

Khvorostyanov, V. I. and Curry, J. A.: Terminal velocities of droplets and crystals: Power laws with continuous parameters over the size spectrum, J. Atmos. Sci., 59, 1872-1884, 2002.

Kollias, P. and Albrecht B.: The turbulence structure in a continental stratocumulus cloud from millimeter-wavelength radar observations, J. Atmos. Sci., 57, 2417-2434, 2000.

Kollias, P. and Albrecht B.: Vertical velocity statistics in fairweather cumuli at the ARM TWP Nauru Climate Research Facility, J. Clim., 23, 6590-6604, 2010.

Kollias, P., Albrecht, B., Lhermitte, R., and Savtchenko, A.: Radar observations of updrafts, downdrafts, and turbulence in fairweather cumuli, J. Atmos. Sci., 58, 1750-1766, 2001.

Lafore, J. P., Stein, J., Asencio, N., Bougeault, P., Ducrocq, V., Duron, J., Fischer, C., Hereil, P., Mascart, P., Pinty, J. P., Redelsperger, J. L., Richard, E., and Vila-Guerau de Arellano, J.: The Meso-NH Atmospheric Simulation System. Part I: Adiabatic formulation and control simulations, Ann. Geophys., 16, 90-109, doi:10.5194/angeo-16-90-1998, 1998.

Le Moigne, P.: SURFEX scientific documentation. On-line documentation available online at: http://www.cnrm.meteo.fr/surfex/ doc_exter/surfex_scidoc.pdf, 2009.

Liu, Y., Geerts, B., Miller, M., Daum, P., and McGraw, R.: Threshold radar reflectivity for drizzling clouds. Geophys. Res. Lett., 35, L03807, doi:10.1029/2007GL031201, 2008.

Lohmann, U., Feichter, J., Chuang, C. C., and Penner, J. E.: Prediction of the number of cloud droplets in the ECHAM GCM, J. Geophys. Res., 104, 9169-9198, 1999.

Lu, M.-L., Sorooshian, A., Jonsson, H. H., Feingold, G., Flagan, R. C., Seinfeld, J. h.: Marine stratocumulus aerosol-cloud relationships in the MASE-II experiment: Precipitation susceptibility in eastern Pacific marine stratocumulus. J. Geophys. Res., 114, D24203, doi:10.1029/2009JD012774, 2009.

Mlawer, E. J., Taubman, S. J., Brown, P. D., Iacono, M. J., and Clough, S. A.: Radiative transfer for inhomogeneous atmospheres: RRTM, a validated correlated-k model for the long wave, J. Geophys. Res., 102, 16663-16682, 1997.

Morcrette, J.-J.: Radiation and cloud radiative properties in the ECMWF operational weather forecast model, J. Geophys. Res., 96D, 9121-9132, 1991.
O’Connor, E. J., Hogan, R. J., and Illingworth, A. J.: Retrieving stratocumulus drizzle parameters using doppler radar and lidar. J. Appl. Meteor., 44, 14-27, 2005

Pergaud, J., Masson, V., Malardel, S., and Couvreux, F.: A parameterization of dry thermals and shallow cumuli for mesoscale numerical weather prediction. Bound-Lay. Meteorol., 132, 83-106, 2009.

Pinty, J. P. and Jabouille, P.: A mixed-phase cloud parameterization for use in a mesoscale non-hydrostatic model: simulations of a squall line and of orographic precipitation. Preprints of Conference On Cloud Physics, Everett, WA, Am. Meteorol. Soc., 217-220, 1998.

Rodts, S. M. A., Duynkerke, P. G., and Jonker, H. J. J.: Size distributions and dynamical properties of shallow cumulus clouds from aircraft observations and satellite data. J. Atmos. Sci., 60, 1895-1912, 2003.

Rogers, R. R.: A short course in cloud physics. A. Wheaton \& Co., 266 pp., 1976.

Seity, Y., Brousseau, P., Malardel, S., Hello, G. Bénard, P., Bouttier, F., Lac, C., and V. Masson: The AROME-France convective scale operational model, Mon. Weather Rev., 139, 976-991, doi:10.1175/2010MWR3425.1, 2010.

Skamarock, W. C.: Evaluating mesoscale NWP models using kinetic energy spectra, Mon. Weather Rev., 132, 3019-3032, 2004.

Snider, J. R., Guibert, S., Brenguier, J.-L., and Putaud, J.-P.: Aerosol activation in marine stratocumulus clouds: 2. Köhler and parcel theory closure studies. J. Geophys. Res., 108, 8629, doi:10.1029/2002JD002692, 2003.

Zhu, P. and Zuidema, P.: On the use of PDF schemes to parameterize sub-grid clouds. Geophys. Res. Lett., 36, L05807, doi:10.1029/2008GL036817, 2009.

Zubler, E. M., Folini, D., Lohmann, U., Lüthi, D., Muhlbauer, A., Pousse-Nottelmann, S., Schär, C., and Wild, M.: Implementation and evaluation of aerosol and cloud microphysics in a regional climate model, J. Geophys. Res., 116, D02211, doi:10.1029/2010JD014572, 2011. 